\title{
GPS-TEC Variation during Low to High Solar Activity Period (2010-2014) under the Northern Crest of Indian Equatorial Ionization Anomaly Region
}

\author{
Nilesh C. Patel*, Sheetal P. Karia, Kamlesh N. Pathak \\ Department of Applied Physics, S.V. National Institute of Technology, Surat, India \\ Email: *patel.nilesh569@gmail.com,d14ph004@ashd.svnit.ac.in
}

How to cite this paper: Patel, N.C., Karia, S.P. and Pathak, K.N. (2017) GPS-TEC Variation during Low to High Solar Activity Period (2010-2014) under the Northern Crest of Indian Equatorial Ionization Anomaly Region. Positioning, 8, 13-35. https://doi.org/10.4236/pos.2017.82002

Received: April 13, 2017

Accepted: May 28, 2017

Published: May 31, 2017

Copyright ( 92017 by authors and Scientific Research Publishing Inc. This work is licensed under the Creative Commons Attribution International License (CC BY 4.0).

http://creativecommons.org/licenses/by/4.0/

(c) † Open Access

\begin{abstract}
The measurements of ionospheric TEC (total electron content) are conducted at a low latitude Indian station Surat $\left(21.16^{\circ} \mathrm{N}, 72.78^{\circ} \mathrm{E}\right.$ Geog.), which lies under the northern crest of the equatorial anomaly in Indian region. The data obtained are for a period of five years from low to high solar activity (20102014) using GPS (Global Positioning System) receiver. In this study, we report the diurnal and seasonal variation of GPS-TEC, dependence of GPS-TEC with solar activity, geomagnetic condition and EEJ strength. From the seasonal analysis, it is found that greater values of the GPS-TEC are observed during equinox season followed by winter and summer. The appearance (in the year 2011 and 2014) and disappearance (in the year 2010 and 2012) of "winter anomaly" have been observed at the station. From the correlation of GPS-TEC with different solar indices, i.e. solar EUV flux, F10.7 cm solar radio flux and Zurich sunspot number (SSN), it is concluded that the solar index EUV flux is a better controller of GPS-TEC, compared to F10.7 cm and SSN. Further, it is observed that there is no effect of rising solar activity on correlation. Moreover, the percentage variability of GPS-TEC and the standard deviation of GPS-TEC obtained for quiet and disturbed days show that dependence of GPS-TEC on geomagnetic condition is seasonal. Also, there is a positive correlation observed between GPS-TEC and EEJ strength.
\end{abstract}

\section{Keywords}

Total Electron Content (TEC), Equatorial Ionization Anomaly (EIA), Solar Cycle, Equatorial Electrojet (EEJ) Strength

\section{Introduction}

The partially ionized region of the upper atmosphere called the earth's ionos- 
phere, reaches altitudes ranging above $60 \mathrm{~km}$ from the surface of the earth. The ionospheric plasma density in the ionosphere exhibits significant variations with time (sunspot cycle, seasonal, diurnal, latitude, longitude, solar and geomagnetic activities), which can result in change of special vital ionospheric parameters such as total electron content (TEC). TEC is expressed in units of TECU (1TECU $=10^{16}$ electrons per square meter), which is the altitude integral parameter of electron density, can be defined as of the total numeral of electrons from satellite to receiver path in a single square meter cross-section area. The main contribution to the maximum TEC in the ionosphere is at the F-region density that mainly affects the radio wave propagation [1] [2]. In the equatorial low latitude ionosphere at F-region, the ionization density distribution is characterized by a trough at the equator and dual crests on either side of the equator, nearly at about $\pm 17^{\circ}$ magnetic latitudes are called as the crests of EIA. Due to the complexity in dynamic processes involved in ionization of the equatorial low latitude ionosphere at F-region, the morphology of this region becomes significant to study.

The Global positioning system (GPS) signal propagating through the ionosphere is advanced in phase and delayed in time. This time delay being a function of electron density when measured by using dual frequency receiver can compute the TEC. So, the GPS receiver is one of the most practicable tools for TEC study [3] [4]. The ionospheric delay constitutes the major source of error for a single frequency GNSS operation. The sensitivity of the ionospheric range delay to TEC for the primary GPS signal is $0.162 \mathrm{~m} / \mathrm{TECU}$ [5]. The TEC in the upper atmosphere plays a crucial role in the determination of the range delays by the electromagnetic signals while traversing through the ionosphere [6]. According to Chowdhary et al. [7] the development and the discrepancy of the EIA in electron density are reflected in TEC as the F layer forms the largest part of TEC. So, it is important to study of TEC.

Apart from various locations in globe several researchers have been investigated morphological features of TEC such as the diurnal, monthly, seasonal, latitudinal and solar activity variation using various techniques, e.g. in Africa, [8] [13], in South America, [14] [15] [16] [17] [18] over China [19] [20], Huo et al. [21] and Perevalova et al. [22] over North America, Zakharenkova et al. [23] over Japan; Venkatesh et al. [24] [25] [26] over Brazil and many more. Ionospheric TEC variations have been investigated in the Indian region, using this data and other separate TEC measurements at Surat [27], Agra [28] and other different stations, namely Trivandrum, Waltair, Raipur and Delhi [6].

The GPS-TEC data for the Surat station (located under the northern crest of the equatorial ionization anomaly in Indian sector) have been analyzed earlier in the year 2009 at low solar activity period [27]. However, the analysis of high solar activity has never been performed for this station. Further, we obtained correlation coefficient between GPS-TEC and solar indices, especially to the intensity of the ascending phase of the $24^{\text {th }}$ solar cycle being subdued. 


\section{Data Analysis}

Since 2008, the dual frequency NovAtel GSV4004B GPS ionospheric scintillation and TEC monitor (GISTM) receiver continuously records the GPS data at the Department of Applied Physics (APD), SardarVallabhbhai National Institute of Technology (S.V.N.I.T), at Surat station $\left(21.16^{\circ} \mathrm{N}, 72.78^{\circ} \mathrm{E}\right.$, Geog.) in India. The GSV4004B GPS receiver tracks up to 11 satellites at a time, which are at different elevation angles [29]. The data is collected at every minute, which do not include the $50-\mathrm{Hz}$ sampled raw data, but the reduced TEC and S4 index and other parameters are included. To extract TEC from the GPS observation file, the pseudorange measurements on $\mathrm{L} 1(1575.42 \mathrm{MHz})$ and $\mathrm{L} 2(1227.60 \mathrm{MHz})$ frequencies have been considered. The ionospheric delay can be expressed in terms of the signal carrier frequency as follows:

$$
\delta_{\text {ion }}\left(f_{c}\right)=(40.3 \mathrm{TEC}) /\left(f_{c}^{2}\right)
$$

where, $\delta_{\text {ion }}\left(f_{c}\right)$ is the signal propagation delay at a given carrier frequency.

$$
\mathrm{STEC}=\int_{0}^{s} N \mathrm{~d} r=\left(\frac{f_{2}^{2}}{f_{1}^{2}-f_{2}^{2}}\right) \frac{2 f_{1}^{2}}{K} \Delta P_{1,2}
$$

where; $\Delta P_{1,2}=$ Difference between time delays measured by the L1 and L2, $\mathrm{K}=$ $40.3 \mathrm{~m}^{3} \cdot \mathrm{s}^{-1}, f_{1}=$ Frequency of the L1 wave, $f_{2}=$ Second frequency (L2 wave).

In the above Equation (2), there is a bias error correction, which is different for different satellite-receiver pairs. [30] [31] [32] [33] reported that if accurate estimates of the ionospheric TEC are to be obtained, the differential instrumental biases must be removed. In the present study, the receiver part of the bias is corrected by taking the value supplied by the manufacturer by calibrating the receiver against Wide Area augmentation system (WAAS). The satellite bias error corrections are different for different satellite-receiver pairs. The magnitudes of these biases per PRN, in nanoseconds were used in TEC calculations. The biases are calculated by the International GNSS Service (IGS). Calculation details, analysis, and results are available at (http://aiuws.unibe.ch/spec/dcb.php). These values are frequently updated. The detailed explanation is given in [34] [35] [36] [37]. The slant TEC measurements made are the sum of the real slant TEC, the GPS satellite differential delay $b_{S}$ (satellite bias) and the receiver differential delay, $b_{R}$ (receiver bias). Except when at the zenith, the GPS satellite transmits the signal to the reference station through the ionosphere at some oblique angle. To remove the effect of the increased path length due to obliqueness, the STEC needs to be multiplied by a slant factor, $S(E)$.

Therefore, the vertical TEC can be expressed as:

$$
\begin{aligned}
\mathrm{VTEC}= & \left(\mathrm{STEC}-\left[b_{R}+b_{S}\right]\right) / S(E) \\
& S(E)=1 /\left(\cos \chi^{\prime}\right)
\end{aligned}
$$

where,

$$
\cos \chi^{\prime}=\sqrt{1-\left(\frac{R_{x} \cos \chi}{R_{x}+h_{m}}\right)^{2}}
$$


$R_{x}=$ Mean earth radius, $6371 \mathrm{~km}, h_{m}=$ altitude of the IPP, $\chi=$ elevation angle and $\chi^{\prime}=\left(90^{\circ}-\chi\right)[4][38]$.

The ionosphere puncture point (IPP) is where the GPS signals travel through the maximum electron density layer of the ionosphere. The mean ionospheric height of $350 \mathrm{Km}$ is used for the determination of IPP locations, which is found to be valid for elevation $>50^{\circ}$ in a low latitude sector [39]. In the present study, TEC data collected from the low solar activity to high solar activity periods between January-2010 to February-2015 at the observing station are being used. The data for the months of August-2013, November-2013, December-2013, January-2014 and February-2014 were unavailable due to some technical issues. The analysis is limited to geomagnetic quiet conditions.

Rastogi and Klobuchar [40] showed that the difference between the corresponding $\Delta \mathrm{H}$ values at the two stations gives the electrojet contribution. For this, we use the hourly values of $\Delta \mathrm{H}$ at Tirunelveli (Code: TIR, $8.7^{\circ} \mathrm{N}, 77.8^{\circ} \mathrm{E}$, Goeg.) and $\Delta \mathrm{H}$ at Alibag (Code: $\mathrm{ABG} 18.6^{\circ} \mathrm{N}, 72.8^{\circ} \mathrm{E}$, Goeg.) to characterize the strength of EEJ on each day as given by the relationship, EEJ strength $=\Delta H_{T I R}-\Delta H_{A B G}$ [41] [42] [43] [44]. It is to note that $\Delta H$ is the normalized value of horizontal component and is obtained by removing night time (18:00 LT to 23:00 LT) mean values of $\mathrm{H}$. To calculate the EEJ strength we have first chosen magnetically quiet days to avoid any disturbances caused due to geomagnetic conditions. Further, the mean of night time data are considered as zero level. Hourly values of Tirunelveli station $(\Delta \mathrm{H})$ is then subtracted from its zero level, this gives $\Delta \mathrm{H}_{\mathrm{TIR}}$. Similarly, $\Delta \mathrm{H}_{\mathrm{ABG}}$ is obtained and the difference $\Delta H_{T I R}-\Delta H_{A B G}$ is calculated to obtain EEJ strength. Here, to obtain EEJ strength, one-hour magnetic field data from ground based magnetometers is used in IAGA2002 format which is provided by the Indian Institute of Geomagnetism, Mumbai, India. The strength of the EIA is normally controlled by the equatorial electrojet (EEJ) strength, which shows significant temporal, day-to-day- seasonal, solar cycle and longitudinal variation reported by different researchers [26] [39] [45].

The daily solar indices (EUV flux, F10.7 cm and SSN) of solar variability, Zurich sunspot number (SSN) and solar flux F10.7 data are obtained from (http://www.ngdc.noaa.gov) and solar EUV flux (SFU) data are obtained from (http://lasp.colorado.edu/lisird/whi_ref_spectra/) for the period 2010-2014.

\section{Results and Discussion}

To study the GPS-TEC variation with local time, season, solar activity and geomagnetic condition, we have used a data base from January 2010 to December 2014 situated under the northern crest of the equatorial anomaly region, Surat. The results are discussed below.

\subsection{Diurnal Variation of GPS-TEC}

For Surat station the diurnal variation of hourly mean GPS-TEC is obtained, such that there is a gradual decrease in GPS-TEC between 00:00 to 05:00 IST 
(IST $=$ local time $(\mathrm{LT})=\mathrm{UT}+5: 30 \mathrm{hrs})$ pre-dawn to sun up period, reaching a minimum between 05:00 to 06:00 IST over the Indian sector and steadily increase with the time of day attaining a maximum in the noon to afternoon and a gradual decrease after sunset. The observations of diurnal variation in GPS-TEC show that the time at which GPS-TEC reaches the diurnal peak vary from month to month and day to day. In general, the diurnal GPS-TEC attained their peak values mostly between 13:00 and 16:00 IST and the minimum in the GPS-TEC flat during most of the night time hours; i.e. from 22:00 to 06:00 during both low and high solar activity phase.

One very important noticeable feature that is the day-to-day uncertainty in the variation of GPS-TEC, particularly during the middle of the day to pre-dawn hours, which is of serious worry in forecasting, as well as in navigation system. This uncertainty in the day-to-day variation, seasonal variation in TEC [6] [39] [46] [47] may be attributed to: 1) the changes in the activity of the Sun itself and to the connected changes in the intensity of the incoming radiations; 2) the zenith angle $(\chi)$ at which they impinge on the Earth's upper atmosphere, in addition to the changes which take place in the Earth's magnetic field; 3 ) the equatorial electrojet (EEJ) strength, added to the effects due to the dynamics of the EIA and 4) the meridional neutral winds. The diurnal variation of GPS-TEC may also be due to the motion of the ionized particles across the geomagnetic fields by tidal winds [48]. Recently, Jonah et al. [49] studied GPS-TEC variation during high and low solar activity phase over the South American sector. They reported that a day-to-day uncertainty in the variation of GPS-TEC contains a component driven by planetary waves improved by tides as they propagate upward. A strong vertical coupling through the increasing propagating waves can also give rise to day-to-day oscillation in GPS-TEC. Their study also illustrates that apart from solar radiation effect, variations in the meridional wind or zonal winds also play an important role corresponding to the changes in GPS-TEC.

\subsection{Seasonal Variation of GPS-TEC}

To study the seasonal variation of GPS-TEC for different years (2010-2014), each year has been classified into three seasons, i.e. equinoxes (March, April, September and October), summer (May, June, July and August) and winter

(November, December of current year) and (January, February of successive year).

Hourly mean of diurnal GPS-TEC for four months at a particular hour were obtained to derive the seasonal mean for all these three seasons, Figure 1(a) represents variation during different seasons recorded at Surat for a period of March 2010 to February 2011. Similarly, Figure 1(b) 2011 Figure 1(c) 2012 Figure 1(d) 2013 and Figure 1(e) 2014 respectively. In general it is seen from Figures 1(a)-(e) that the greater values of the GPS-TEC were observed in equinoctial months for all five years, followed by winter in the year 2011 and 2014 also in summer for the year 2010 and 2012. The highest value of GPS-TEC is recorded for equinoctial months in the year 2014 ( 130 TECU), 2012 ( 91 TECU), 


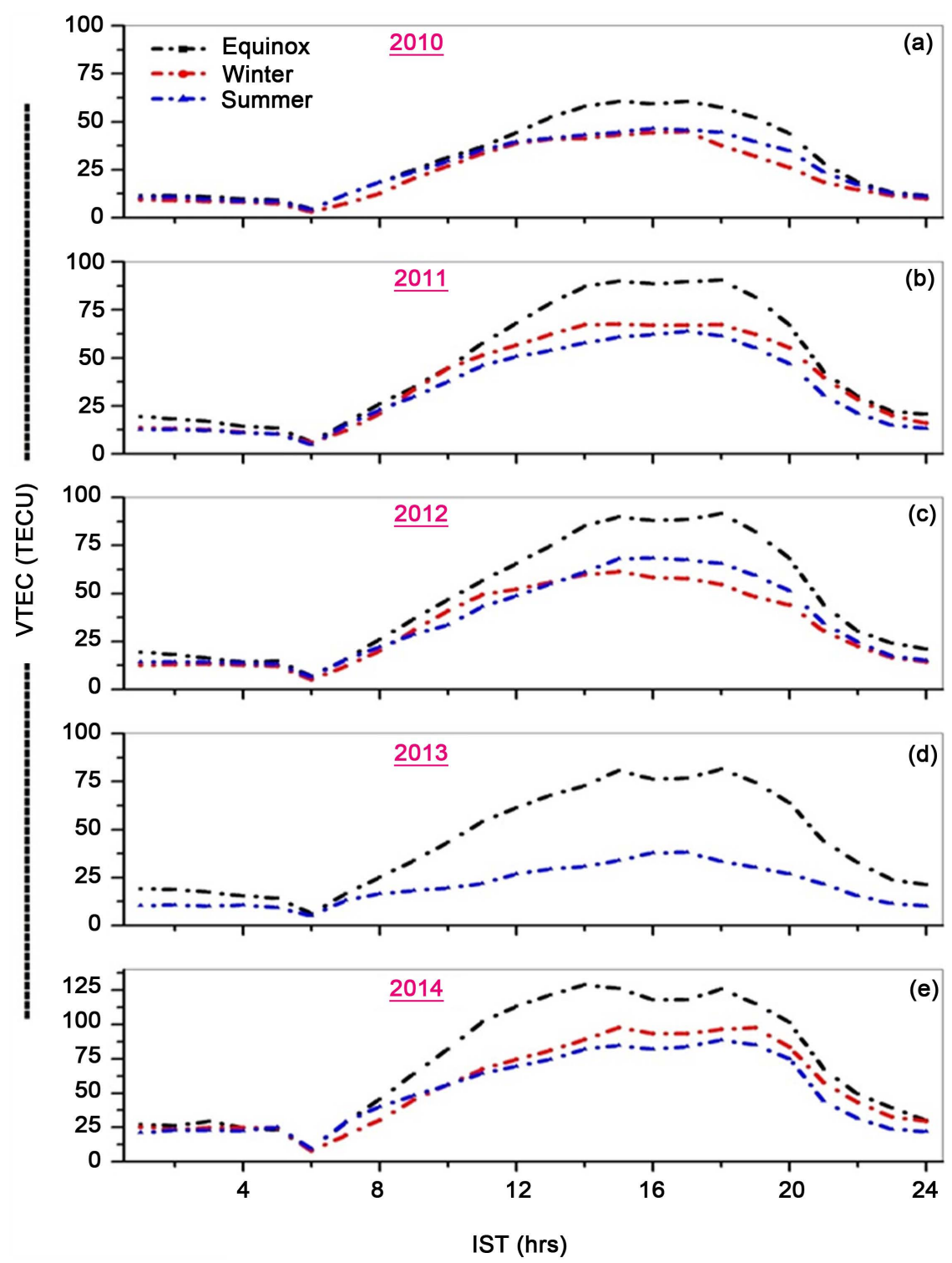

Figure 1. Plots of seasonal variation of GPS-TEC for the years (a) 2010 (b) 2011 (c) 2012 (d) 2013 (e) 2014 from normal quiet period under the northern crest of EIA at Surat.

2011 ( 90 TECU), 2013 ( 81 TECU) and 2010 ( 60 TECU) is shown in Figure 2.

From Figure 1 we can see that the forenoon rate of ionization in equinox season is faster than that in winter and summer season. The plot in Figure 1 and Figure 2 states that the amplitude of the diurnal maximum is higher in the equinoctial months, which may be due to higher thermospheric $\left[\mathrm{O} / \mathrm{N}_{2}\right]$ ratio and EEJ strength over the Surat station. It is normally accepted that the thermospheric neutral composition has a direct control on the seasonal variation of GPS-TEC [44] [50]. Oryema et al. [51] and the references therein reported that, during the daytime in an equinoctial season, the sun is overhead the equator and temperature level at the equator are hotter than at the poles, therefore from the equator meridional wind flows towards the pole. This flow of meridional wind 


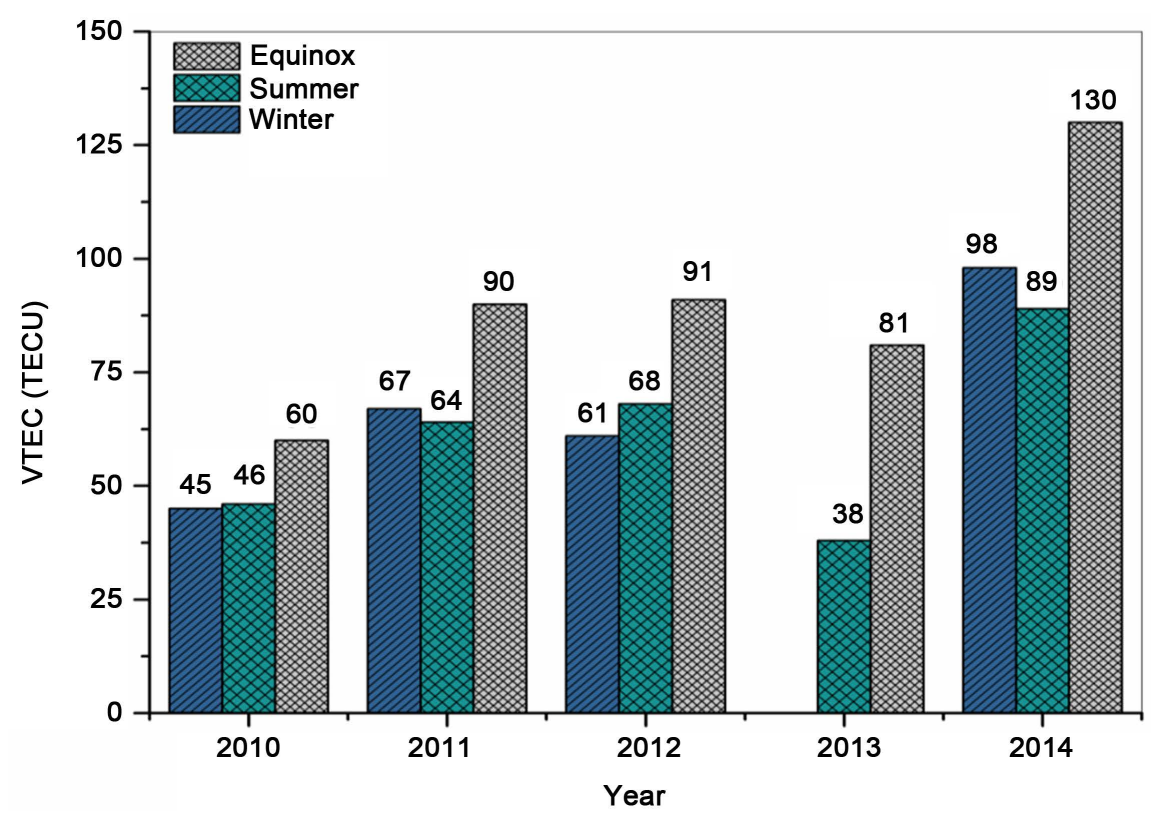

Figure 2. Plots of seasonal maximum GPS-TEC for the years 2010-2014 from normal quiet period under the northern crest of EIA at Surat.

changes the neutral composition and $\left[\mathrm{O} / \mathrm{N}_{2}\right]$ increases at low and equatorial latitude regions. In equinox, this increase will be maximum. At $350 \mathrm{~km}$ height (F2 layer), $\mathrm{N}_{2}$ dissociation is the most significant method which removes ambient electrons. Hence, the decrease in thermospheric atomic/molecular $\left[\mathrm{O} / \mathrm{N}_{2}\right]$ ratio will outcome in greater electron density and therefore in equinox TEC will be highest [44] [52] [53] [54].

Compared to other seasons, the summer GPS-TEC is lowest for the year 2011 ( 64 TECU), 2013 ( 38 TECU) and 2014 ( 89 TECU). However, for the year 2010 ( 45 TECU) and 2012 ( 61 TECU) lowest GPS-TEC is observed during the winter months. Further, the higher GPS-TEC in the winter than in the summer for the year 2011 and 2014 at low latitudes over Surat station shows "winter anomaly" (or seasonal anomaly). The most motivating aspects of GPS-TEC observations at low latitudes, that have been studied by a number of researchers, is the presence of winter anomaly in the anomaly crest region [27] [39] [43] [55] [56] [57] [58] [59]; while other researchers have also studied the disappearance of "winter anomaly" [44] [47] [60]-[66]. The "winter anomaly" defined as the winter electron density remains greater than the summer electron density [67]. The winter anomaly is caused by the increase in the thermospheric atomic/molecular $\left[\mathrm{O} / \mathrm{N}_{2}\right]$ ratio from the southern and northern hemisphere reported by a number of authors [50] [57] [68] [69] [70] [71]. Thus, the appearance of winter anomaly in EIA crest strength has been attributed to an energy input discrepancy between S-N hemisphere [70]; change in season by a neutral gas composition [43] [57]; chemical recombination and solar radiation [67]; solar zenith angle [50] [59]; and trans-equatorial summer to winter neutral wind [72]. According to, Karia and Pathak [27] the meridional winds may contribute to the seasonal variations of GPS-TEC, particularly at which the thermospheric wind effects are 
mainly strong. Research by Kumar et al. [59] reported the presence of winter anomaly in the EIA crest throughout the period 2005-2009 only, excluding during the deep solar minimum year 2007-2008. However, they further attributed that this may be due to a combined effect of the magnetic field geometry and solar zenith angle. The disappearance of the winter anomaly around the crest of the EIA is credited to the increase in altitude of the $\mathrm{F}$ peak ionization in the summer season and greater $\mathrm{E} \times \mathrm{B}$ drift velocity, although thermospheric $\left[\mathrm{O} / \mathrm{N}_{2}\right]$ ratio is higher in winter season [70]. Thus, the disappearance of winter anomaly in EIA crest may be attributed to a mechanical effect of the equator-ward neutral winds [66].

March 2014 to February 2015 is a high solar activity period. For the high solar activity period the nighttime resurgence of the anomaly (occasioning a secondary peak in GPS-TEC) associated to the evening prereversal enhancement is observed at low latitude station Surat as shown in Figure 1(e). This type of similar results observed for high solar activity period 2001 over South American Sector by Jonah et al. [49].

In order to check the reliability of data of one GPS station (Surat), we analyzed the GPS-TEC data obtained from three different stations (Bangalore, Hyderabad and Lucknow) available from the IGS network in RINEX format. The results are presented in Figure 3. It can be seen that the seasonal trends of TEC observed at these three stations are similar to those at Surat. Also the disappearance of winter anomaly is observed at all three stations for the year 2012 as observed at Surat station.

\subsection{GPS-TEC Variation with Solar Activity}

The main source of insolation on the earth is solar energy, in the form of radiation and charged particles. The earth's upper atmosphere takes in those solar radiations derived from heating, ionization and dissociation. The earth's ionosphere is constructed by the ionizing effect of solar extreme ultraviolet rays. In general, the upper atmosphere of the earth, solar radiations is measured in expression of solar indices, i.e. 1) The solar EUV flux $(0.1 \mathrm{~nm}-50 \mathrm{~nm})$ : The daily average of full solar disk EUV flux recorded in the $0.1-50 \mathrm{~nm}$ spectral band and measured at $1^{\circ} \mathrm{AU}$ (astronomical unit). The solar EUV flux data, represented by units of $10^{10}$ photons $\mathrm{cm}^{-2} \cdot \mathrm{s}^{-1}$, has been used from the Solar EUV Monitor (SEM) on-board the Solar and Heliospheric Observatory (SOHO) satellite. 2) F10.7 cm solar radio flux $(2800 \mathrm{MHz})$ : The Solar flux is a compute of the intensity of solar radio emission at the reciprocal of the period of $2800 \mathrm{MHz}$ also known as 10.7 $\mathrm{cm}$ flux (the wavelength of the radio signals at $2800 \mathrm{MHz}$ ) commonly measured in solar flux unit ( 1 s.f.u. $=10^{22} \mathrm{~W} \cdot \mathrm{m}^{-2} \cdot \mathrm{Hz}^{-1}$ ) and is proportional to sunspot activity, and 3) Zurich sunspot number (SSN). Figure 4 shows yearly mean of different solar indices, i.e. a) solar EUV flux, b) F10.7 cm solar radio flux and c) Zurich sunspot number (SSN) with respect to GPS-TEC. Pattern of all three solar indices with GPS-TEC in low and moderate in the solar activity year 2010 and 2011, also high solar activity year 2013 and 2014 trend matches well except for the year 2012 . 


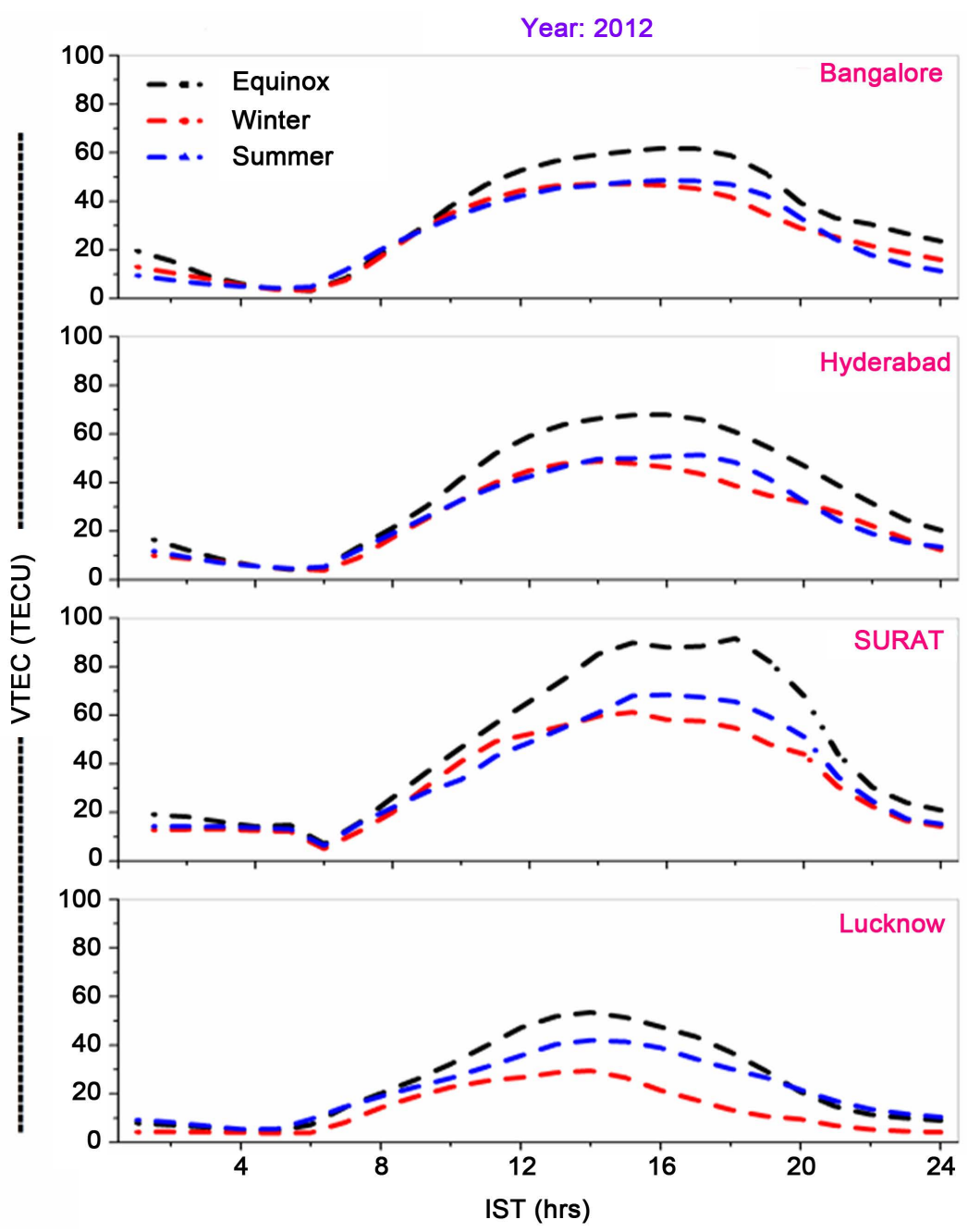

Figure 3. Plots of seasonal variation of GPS-TEC for the different Indian stations (Bangalore, Hyderabad, Surat and Lucknow) for the year 2012.

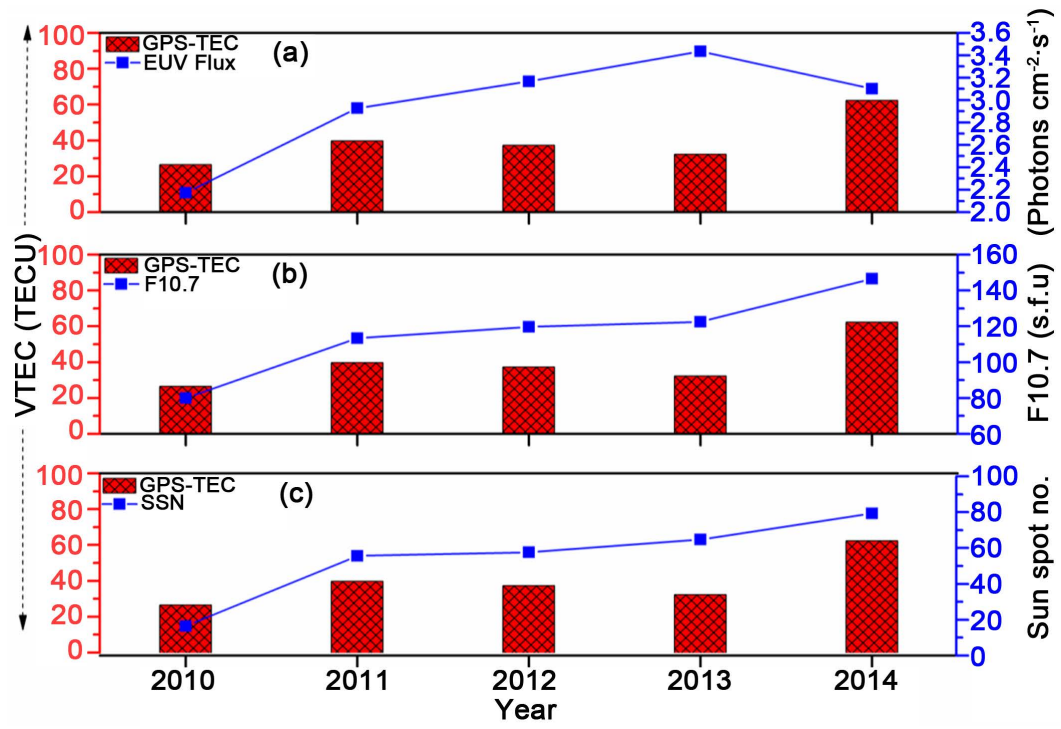

Figure 4. Trend of GPS-TEC of different years with different solar index (a) EUV flux (photons $\mathrm{cm}^{-2} \cdot \mathrm{s}^{-1}$ ) (b) F10.7 $\mathrm{cm}$ (s.f.u.) and (c) Zurich sunspot number (SSN). 
In an effort to know which solar index represents the ionospheric GPS-TEC well at Surat, we obtain the correlation between TEC obtain at Surat and all the solar indices is shown as Figure 5. The left column shows the correlation between daily average GPS-TEC with EUV flux values (photons $\mathrm{cm}^{-2} \cdot \mathrm{s}^{-1}$ ) and the correlation between daily average GPS-TEC with respective F10.7 cm (s.f.u.) values is shows in the middle column for the year 2010 to 2014. The GPS-TEC correlation coefficient ( $r)$ with EUV flux value for the year 2010 to be $(r=0.405)$ followed by the year $2011(\mathrm{r}=0.847), 2012(\mathrm{r}=0.409), 2013(\mathrm{r}=-0.164)$ and $2014(\mathrm{r}=0.600)$. The GPS-TEC correlation coefficient $(\mathrm{r})$ with solar radio flux F10.7 $\mathrm{cm}$ have been observed for the year $2010(\mathrm{r}=0.183)$ and for the year 2011 $(\mathrm{r}=0.649), 2012(\mathrm{r}=0.193), 2013(\mathrm{r}=-0.113)$ and $2014(\mathrm{r}=0.350)$ respectively. The GPS-TEC correlation coefficient ( $r$ ) with a Zurich sunspot number (SSN) value in the right column for the year 2010 found to be $(r=0.192)$ and for the year $2011(\mathrm{r}=0.69), 2012(\mathrm{r}=0.276), 2013(\mathrm{r}=-0.114)$ and $2014(\mathrm{r}=0.314)$ respectively. The positive and negative correlation coefficient $(r)$ with different solar indices results also reported by other researchers (Table 1). Research of, Opio et al. [13] studied a longitudinal range $\left(27^{\circ} \mathrm{E}-40^{\circ} \mathrm{E}\right)$ taking all the latitudes of

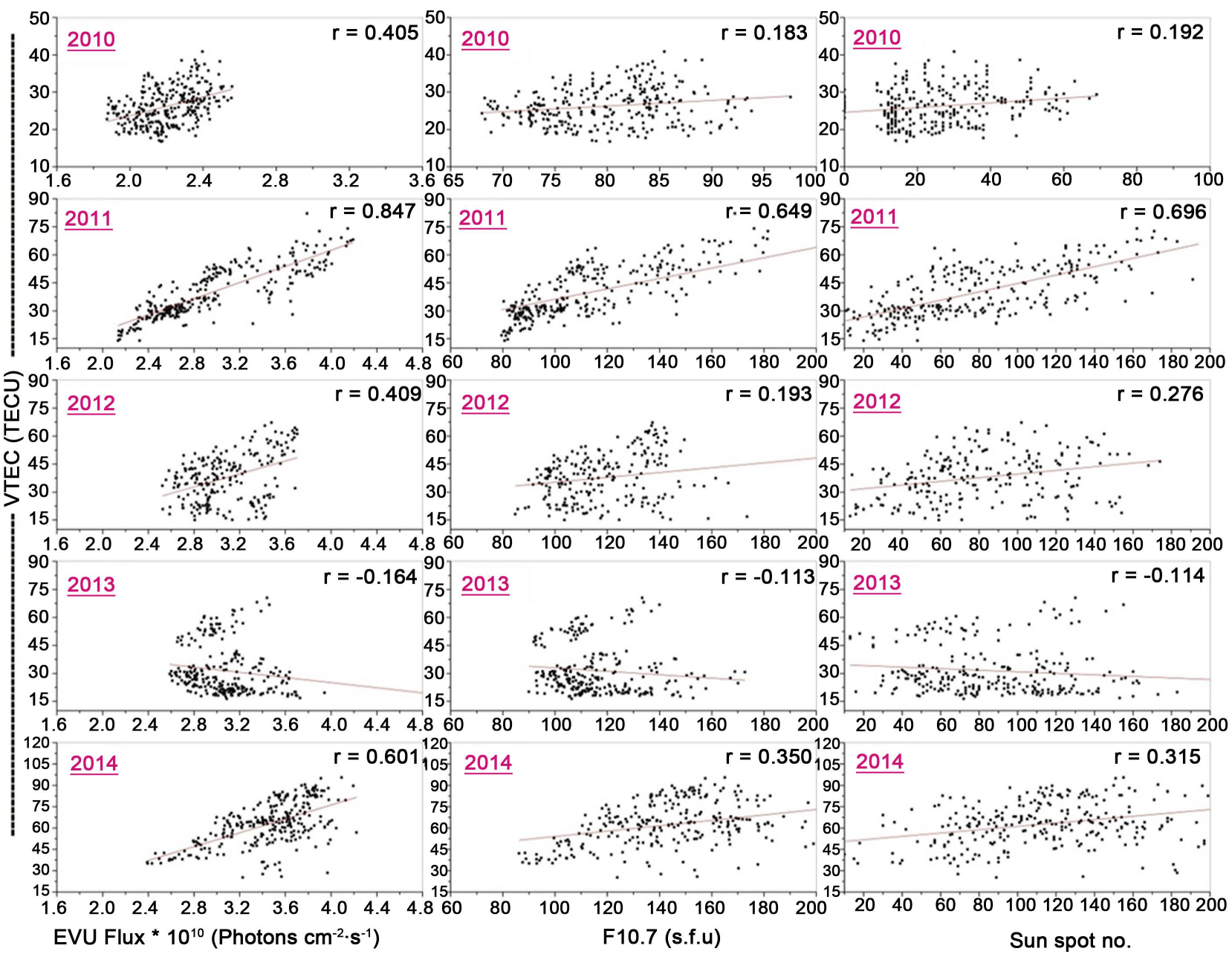

Figure 5. Correlations between GPS-TEC versus three different solar index (Left column) EUV flux (photons $\left.\mathrm{cm}^{-2} \cdot \mathrm{s}^{-1}\right)(\mathrm{Middle}$ column) F10.7 cm (s.f.u.) and (Right column) Zurich sunspot number (SSN) from the normal quiet period 2010-2014. 
Table 1. Literature review of correlation studies of TEC with different solar parameters.

\begin{tabular}{|c|c|c|c|c|c|}
\hline No. & Report & $\begin{array}{l}\text { Ionospheric } \\
\text { parameter }\end{array}$ & Solar indices & Best correlation & Period \\
\hline 1 & Dabas et al. [73] & IEC & Solar EUV flux; $\mathrm{S}_{10.7 \mathrm{~cm}}$ flux and SSN & IEC with EUV flux & $1977-1980$ \\
\hline 2 & Gupta and Singh [74] & IEC & $\mathrm{F}_{10.7}$ solar flux & IEC with $\mathrm{F}_{10.7}$ flux & $1975-80$ and $1986-89$ \\
\hline 3 & Chkraborty and Hajra [75] & TEC & $\mathrm{F}_{10.7}$ solar flux & TEC with $\mathrm{F}_{10.7}$ flux & $1979-90$ \\
\hline 4 & Kumar and Singh [81] & TEC & SSN; $F_{10.7}$ solar flux & TEC with SSN $(=-0.03)$ & $2007-2008$ \\
\hline 5. & Galav et al. [63] & TEC & $\mathrm{F}_{10.7}$ solar flux & TEC with $\mathrm{F}_{10.7}$ flux $(=0.74)$ & $2005-2009$ \\
\hline 6. & Chauhan et al. [28] & TEC & EUV flux, $\mathrm{F}_{10.7}$ solar flux and SSN & TEC with $\mathrm{F}_{10.7}$ flux & 2006-2009 \\
\hline 7. & Chakrabarty et al. [90] & TEC & $\mathrm{F}_{10.7}$ solar flux & TEC with $\mathrm{F}_{10.7}$ flux $(=0.98)$ & 2005-2009 \\
\hline 8. & Opio et al. [13] & TEC & $\mathrm{F}_{10.7}$ solar flux & TEC with $\mathrm{F}_{10.7}$ flux $(=0.75)$ & 2011 \\
\hline 9. & Rama Rao et al. [6] & TEC & EUV flux, $\mathrm{F}_{10.7}$ solar flux and SSN & TEC with $\mathrm{F}_{10.7}$ flux & $2004-2005$ \\
\hline 10. & Liu et al. [77] & TEC & EUV flux and $F_{10.7}$ solar flux & TEC with EUVflux & $1998-2008$ \\
\hline 11. & Shimeis et al. [91] & TEC & SSN & TEC with SSN $(=0.9)$ & $2002-2012$ \\
\hline 12. & Wu et al. [78] & TEC & $\mathrm{F}_{10.7}$ solar flux & TEC with $\mathrm{F}_{10.7}$ flux $(=-0.09)$ & 1996-1997 \\
\hline 13. & Zhao et al. [80] & TEC & $\mathrm{F}_{10.7}$ solar flux & TEC with $\mathrm{F}_{10.7}$ flux (positive) & 1996-2004 \\
\hline 14. & Liu et al. [76] & TEC & $\mathrm{F}_{10.7}$ solar flux and SSN & TEC with SSN $(=0.26)$ & 2006 \\
\hline 15. & Wu et al. [79] & TEC & $\mathrm{F}_{10.7}$ solar flux & TEC with $\mathrm{F}_{10.7}$ flux $(=0.87)$ & $1994-2003$ \\
\hline
\end{tabular}

the African sector using GPS-TEC data over hrao station and reported a high positive coefficient $r$ of $(r=0.75)$ for the year 2011. They found that the September-October equinox registered larger TEC values of 85 TECU with a high daily TEC variability compared to the March - April equinox for the year 2011. They attributed to the sun's radiation intensity in the two equinoxes calculated by the solar flux, whereby in the year 2011 the solar flux $\mathrm{F}_{10.7} \mathrm{~cm}$ registered a value of about $170 \mathrm{sfu}$ in spring equinox than fall equinox with a value of about $130 \mathrm{sfu}$. Our results for the year 2011 are in agreement with them.

Mostly researchers [6] [13] [28] [58] [63] [73]-[81] have focused on the correlation between TEC and $\mathrm{F}_{10.7}$ solar flux. Only a few researchers have focused on the correlation between TEC and Solar EUV flux [6] [28] [73] [77]. According to Prasad et al. [58] the F10.7 index originates mainly at high-temperature transition region of the solar atmosphere, but the solar EUV flux originates in the irregular layer above the Photosphere ("Chromospheres") and to some minor extent in the transition region and corona. At higher solar activity periods the F10.7 $\mathrm{cm}$ flux undergoes stronger fluctuations. During these periods the EUV emissions from higher excited atoms in the solar atmosphere correlate with GPS-TEC.

Table 2 represents the correlation of mean GPS-TEC with all three solar indices during the three seasons, i.e. winter, equinox and summer for the period of March 2010 to February 2011. In Table 2 bold fonts represents a greater value of a correlation with respective season of the year, similarly for the year 2011, 2012, 2013 and 2014 respectively. For each season, the data of four months are grouped together. The electron density in the equatorial and low latitudes de- 
Table 2. The seasonal correlation of mean GPS-TEC with all three solar indices EUV flux (photons $\mathrm{cm}^{-2} \cdot \mathrm{s}^{-1}$ ) F10.7 $\mathrm{cm}$ (s.f.u.) and Zurich sunspot number (SSN) from normal quiet period 2010-2014.

\begin{tabular}{cccccc}
\hline \multicolumn{5}{c}{ Correlation of seasonal mean EIA with seasonal mean } \\
\hline YEAR & 2010 & 2011 & 2012 & 2013 & 2014 \\
\hline EUV $\rightarrow$ TEC & & & & & \\
Winter & $\mathbf{0 . 6 5 8}$ & $\mathbf{0 . 9 3 9}$ & 0.282 & No data & 0.422 \\
Equinox & 0.332 & 0.448 & $\mathbf{0 . 6 5 7}$ & $\mathbf{0 . 1 9 3}$ & $\mathbf{0 . 6 1 3}$ \\
Summer & 0.407 & 0.763 & 0.343 & -0.282 & 0.432 \\
F10.7 $\rightarrow$ TEC & & & & & \\
Winter & 0.35 & $\mathbf{0 . 9 3 8}$ & 0.073 & No data & 0.266 \\
Equinox & $\mathbf{0 . 4 3 4}$ & 0.127 & $\mathbf{0 . 6 0 1}$ & $\mathbf{0 . 0 1 3}$ & 0.139 \\
Summer & 0.351 & 0.392 & 0.078 & -0.253 & $\mathbf{0 . 3 6 3}$ \\
SSN $\rightarrow$ TEC & & & & & \\
Winter & $\mathbf{0 . 3 7 1}$ & $\mathbf{0 . 9 1 8}$ & 0.232 & No data & $\mathbf{0 . 4 4 7}$ \\
Equinox & -0.018 & 0.19 & 0.305 & -0.019 & 0.258 \\
Summer & 0.055 & 0.28 & $\mathbf{0 . 3 2 2}$ & -0.254 & 0.431 \\
\hline
\end{tabular}

pends, on the ionization due to solar radiation and growth of electron density due to transport [58]. For the day-time period, a major part of the electron density at equator is caused by the solar radiation whereas under the northern crest of the EIA location the contribution of plasma is transported because of the fountain effect adds to that created due to solar radiations which are less powerful compared to those at the equator as a result of the solar zenith angle changes. This possibly would be one of the reason for the experimental less correlations between the GPS-TEC and solar indices parameters at a low latitude station under the northern crest of the equatorial ionization anomaly (EIA) region in the Indian sector.

It can be seen that value of correlation coefficient (r) for EUV flux and F10.7 $\mathrm{cm}$ flux is positive for all season except for the summer 2013. The correlation of GPS-TEC and SSN is found to be low as compared to those of EUV flux and F10.7 cm in all seasons. In general correlation coefficient of GPS-TEC with EUV is observed to be better for all season compare to F10.7 and SSN. The daytime maximum GPS-TEC for all day observation are plotted against the corresponding EUV flux which shows the linear positive correlation $(\mathrm{r}=0.63)$ during the period 2010-2014 (see Figure 6). Recently, Bhuyan and Hazarika [64] have studied the ascending half of the solar cycle 24 from 2009 to 2012 over Dibrugarh $\left(27.5^{\circ} \mathrm{N}, 94.9^{\circ} \mathrm{E}\right.$ Geog.) and found a linear positive correlation $(\mathrm{r}=0.56)$ between diurnal maximum GPS-TEC against corresponding solar EUV flux. A research of Chen et al. [82] shows that the relationship between the solar EUV flux and F10.7 cm flux during the deep solar minimum years (2007-2009) is different from the previous solar minimum years, the lessening in two parameters being $5 \%$ in F10.7 cm flux and $15 \%$ in $0.1-50 \mathrm{~nm}$ EUV irradiation compared to 


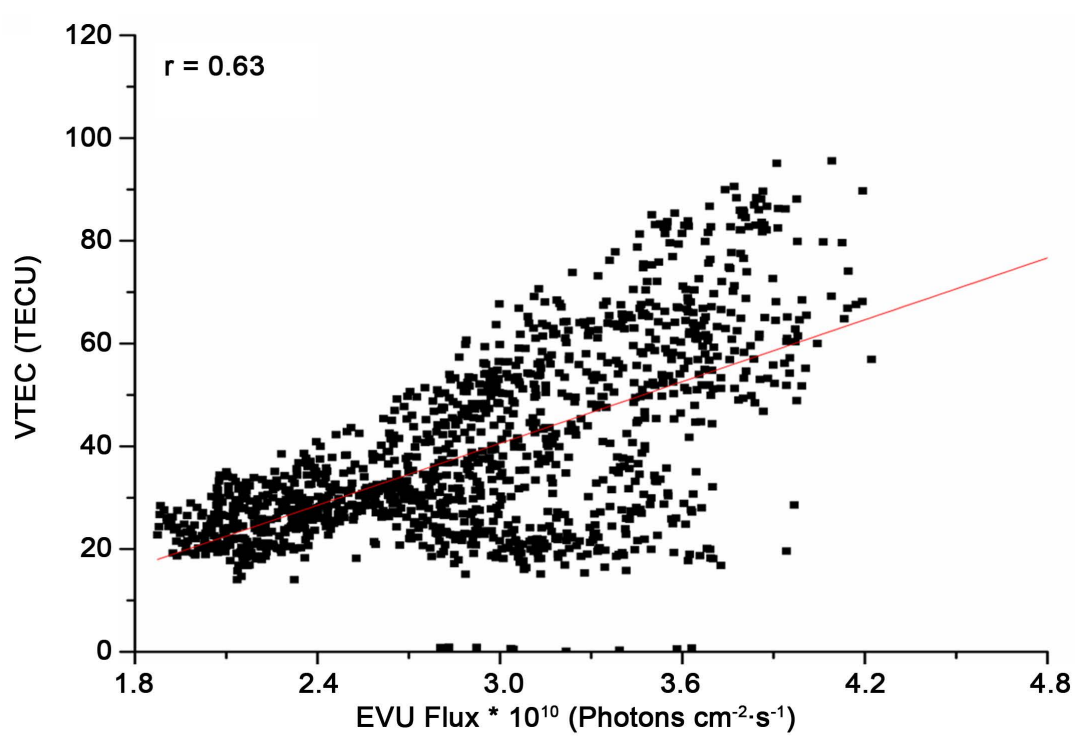

Figure 6. Mass plot for the daily GPS-TEC against corresponding daily EUV flux from January 2010 to December 2014. The solid line is the linear regression trough the data points.

the previous solar minimum. The main reason that controls TEC variations and the variability of thermospheric electron density, composition and temperature of neutral atmosphere is the solar EUV radiation [83] [84]. To obtain the correlation between the decomposed TEC A6 and measured solar index EUV flux and F10.7 cm flux, Yadav et al. [85] found good correlation between decomposed TEC A6 and EUV flux. In general, for the seasonal and annual variation of GPS-TEC with different solar indices at EIA crest region over Surat; India, the solar index EUV flux is a better indicator of GPS-TEC, compare to $\mathrm{F} 10.7 \mathrm{~cm}$ and SSN for low to high solar activity period (2010-2014).

\subsection{Dependence of GPS-TEC with Geomagnetic Condition}

To study the effect of geomagnetic activity on the GPS-TEC, we derived variability of GPS-TEC, for five quiet and five disturbed days in each month for year 2010-2014 taken from the website

http://www.ga.gov.au/oracle/geomag/iqd_form.jsp. There is considerable dayto-day variability about the monthly mean, characterized by the standard deviation $\sigma$ (GPS-TEC). The absolute standard deviation is important in practical applications [86], for our purposes, we prefer to express it as a percentage of the mean value of GPS-TEC, as described [86].

$$
\Sigma(\text { GPS-TEC })=\sigma(\text { GPS-TEC }) /(\text { GPS-TEC })(\%)
$$

The mean values of percentage variability of GPS-TEC ( $\Sigma$ GPS-TEC) for low to high solar activity year 2010 to 2014 situated under the northern crest of the equatorial anomaly region, over Surat station, are shown in Table 3. The differences between two equinox months March and April, and between September and October, are mostly due to the transitions between summer and winter, which was earlier reported by Rishbeth and Mendillo [86]. 
Table 3. The mean values of percentage variability of GPS-TEC ( $\sum$ GPS-TEC \%) for low to high solar activity year 2010 to 2014 during geomagnetically quiet and disturbed days.

\begin{tabular}{ccccccccccc}
\hline \multirow{2}{*}{ Year } & \multicolumn{2}{c}{2010} & \multicolumn{2}{c}{2011} & \multicolumn{2}{c}{2012} & 2013 & 2014 \\
\cline { 2 - 10 } & Q-Days & D-Days & Q-Days & D-Days & Q-Days & D-Days & Q-Days & D-Days & Q-Days & D-Days \\
\hline MAR, & 65.877, & 64.245, & 63.246, & 60.558, & 61.055, & 62.048, & 59.143, & 62.252, & 58.34, & 58.305, \\
APR & 66.49 & 74.927 & 65.977 & 64.276 & 64.875 & 59.369 & 56.367 & 48.996 & 57.135 & 58.142 \\
SEP, & 64.701, & 65.717, & 71.127, & 71.044, & 64.604, & 73.289, & 60.076, & 61.589, & 65.676, & 64.232, \\
OCT & 64.44 & 67.869 & 71.046 & 69.546 & 63.581 & 69.906 & 64.244 & 57.874 & 61.871 & 58.573 \\
JUN, & 56.88, & 59.219, & 58.285, & 58.731, & 54.645, & 49.606, & 50.759, & 49.896, & 51.404, & 52.44, \\
JUL & 56.154 & 57.136 & 61.517 & 58.217 & 61.652 & 55.744 & 51.386 & 52.174 & 53.406 & 50.532 \\
DEC- & 65.28, & 62.498, & 62.888, & 61.315, & 52.938, & 60.574, & No & No & 48.468, & 52.086, \\
JAN & 64.275 & 73.759 & 62.701 & 79.675 & 63.134 & 68.625 & Data & Data & 55.141 & 57.616 \\
\hline
\end{tabular}

Percentage variability of GPS-TEC ( $\sum$ GPS-TEC), during the disturbed days and quiet days is found to be highest in an equinox season in comparison to that in the winter and summer season (except for the year 2010, which is associated with the low solar activity year). Moreover, for both quiet and disturbed conditions we plotted the standard deviation of GPS-TEC against the years 2010-2014 as shown in Figure 7. It is observed that the standard deviation of GPS-TEC is high and it increases with an increase in solar activity (2010-2014) as seen in Figure 7. This could be attributed to the increase in input of energy to the ionosphere from the Sun in high solar activity.

\subsection{Dependence of GPS-TEC on EEJ Strength}

The characteristic of the equatorial electrojet (EEJ) strength plays a very important role in the electron density distribution over equatorial and low latitudes [26] [87] [88]. The EEJ states to an enhanced eastward electric current in the E region because of a strong vertical polarization electric field developed into a latitude band of $\pm 3^{\circ}$ about the dip equator [89]. Rastogi and Klobuchar [40] found dependence of TEC on the equatorial Electrojet by using ATS-6 TEC measurements from the Indian region.

Figure 8 in left column illustrates a comparison of the measured monthly peak values of the GPS-TEC for 2010-2014 with equatorial electrojet (EEJ) strength. The overall trends of TEC obtained from GPS and equatorial electrojet (EEJ) strength are similar in different months of the years of study. It is observed that starting from the year 2010 peak value of GPS-TEC and the peak value of EEJ was maximum during equinox months and minimum during the summer months. Similar results were also found for other years 2011 to 2014. Rama Rao et al. [6] [39] and Venkatesh et al. [26] reported that the EEJ shows a clear seasonal behavior with stronger electrojet strength during equinoctial months over Indian equatorial and low latitude sectors. Kumar et al. [81] found the EIA crest in TEC is maximum in equinox months constitute due to EEJ strength. The research of Rama Rao et al. [39] reported that the positions of the EIA crest and its 


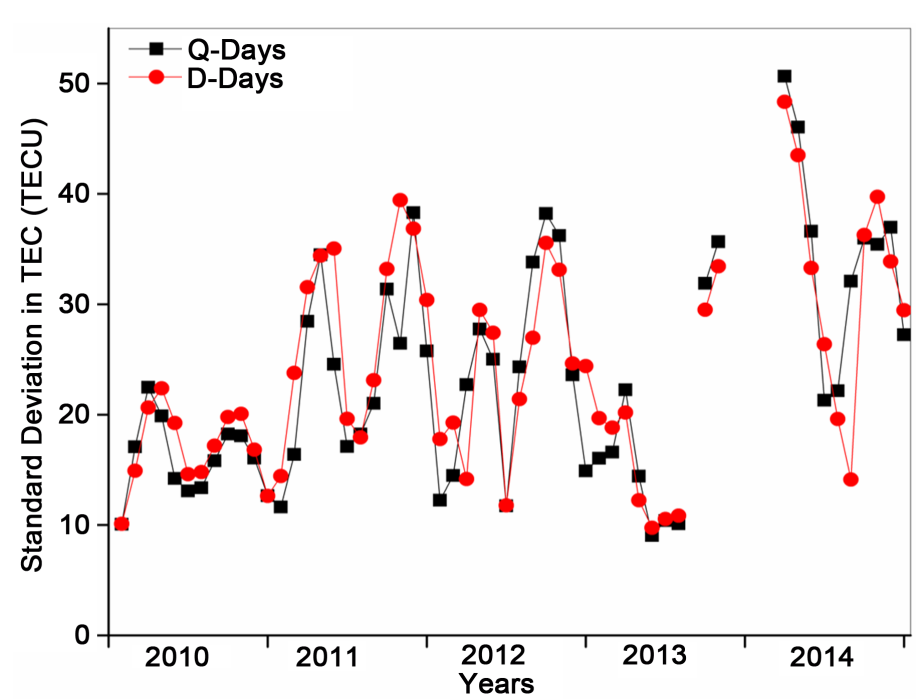

Figure 7. Standard deviation of GPS-TEC during geomagnetically quiet and disturbed days for each month of the year 2010, 2011, 2012, 2013 and 2014 (The data for the months of August 2013, November 2013 to February 2014 were not available due to technical issues).
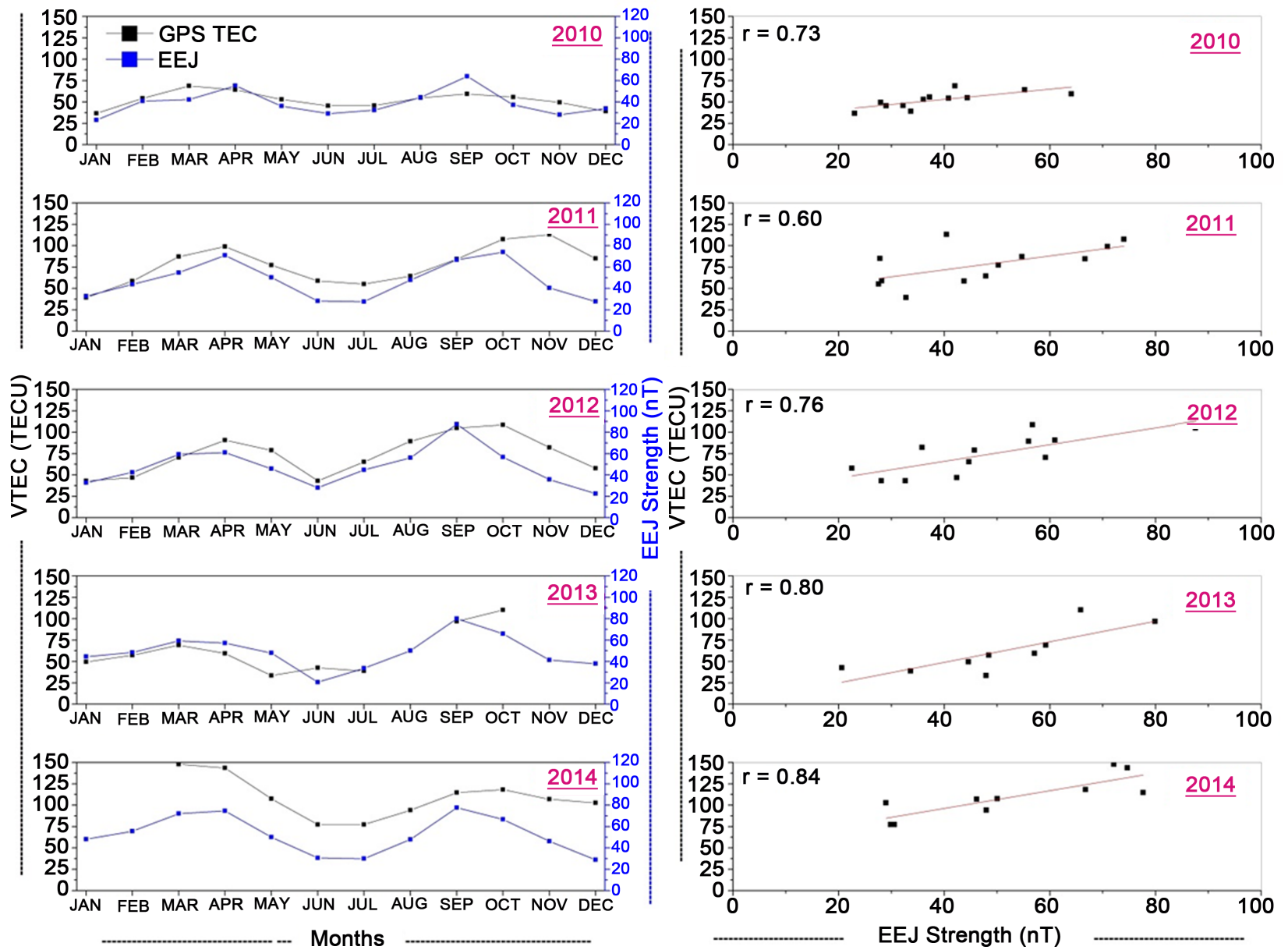

Figure 8. Plot of comparison of the measured monthly peak values of the GPS-TEC with equatorial electrojet (EEJ) strength in left column and the statistical relation of monthly peak values of GPS-TEC with equatorial electrojet (EEJ) strength in right column for 2010-2014. 
peak value in TEC increases with the increase in EEJ strengths. This observation at Surat station indicates is in good agreement with previous researchers reported.

Further, in order to observe the relation between GPS-TEC and EEJ strength we have obtained the correlation coefficient. Figure 8 in the right column, represents the statistical relation of monthly peak values of TEC with equatorial electrojet (EEJ) strength. For each plot in Figure 8 in the right column the correlation coefficients ( $r$ ) were determined and the corresponding fitting is shown by the straight line. The scattered points around the straight line may be due to other factors (local electric fields, neutral winds) contributing to the control of EEJ strength on the day-to-day variation of GPS-TEC. We found a positive correlation coefficient for the year $2010(r=0.73), 2011(r=0.60), 2012(r=0.76)$, $2013(\mathrm{r}=0.80)$ and $2014(\mathrm{r}=0.84)$. The correlation between EIA crest TEC and EEJ strength, Venkatesh et al. [26] found ( $\mathrm{r}=0.53)$ over the Brazilian region; Rama Rao et al. [39] found ( $\mathrm{r}=0.62)$, Bagiya et al. [44] found $(\mathrm{r}=0.71)$ and Venkatesh et al. [26] found $(\mathrm{r}=0.51)$ in the Indian region stations. Our results agree with this study showing the positive relation between GPS-TEC and EEJ strength. However, it is to be noted that, Venkatesh et al. [26] have found a correlation coefficient of $(r=0.5)$ for both Brazilian and Indian sector stations spread over the entire EIA region. The averaging effect might have dampened the correlation whereas we have focused only on the anomaly crest region where we found better correlation.

\section{Summary}

In this study ionospheric GPS-TEC is investigated during the ascending phase of the $24^{\text {th }}$ solar cycle (2010-2014) for a low latitude station under the northern crest of the equatorial ionization anomaly region in the Indian station Surat $\left(21.16^{\circ} \mathrm{N}, 72.78^{\circ} \mathrm{E}\right.$ Geog.). The major findings of the study are as follows:

* The diurnal variation of GPS-TEC demonstrates a gradual increase of total electron content with sunrise around 05:00 and 06:00 IST $($ IST $=$ local time $=$ $\mathrm{UT}+$ 05:30 hrs); peaks up around local afternoon between 13:00 and 16:00 IST, and a gradual decrease after sunset. The diurnal variation amplitude of the GPS-TEC curve varies with evident positions of the Sun over a station.

* While investigating the seasonal variation of GPS-TEC over the region illustrates grater GPS-TEC is highest during the equinox season for the all the years 2010-2014, followed by summer and winter for the year 2010 and 2012. However, winter anomaly was observed for the year 2011 and 2014 (see Figure 1 and Figure 2) this could be attributed to the fact that atomic and molecular ratio $\left[\mathrm{O} / \mathrm{N}_{2}\right]$ which is greater during high solar activity periods in the northern hemisphere. The disappearance of the winter anomaly for the year (2010) may be attributed to low solar activity when the F10.7 solar radio flux is a smaller amount than the threshold level of 90 - 100 solar flux units (1 s.f.u. $\left.=10^{22} \mathrm{Wm}^{-2} \cdot \mathrm{Hz}^{-1}\right)$. However, for the year (2012) its disappearance may due to higher EEJ strength value during summer months compare to winter months 
(see in Figure 8).

* From the correlation of seasonal and annual variation of GPS-TEC with different solar indices at EIA region over the given location, it can be concluded that the solar index EUV flux is a better controller of GPS-TEC, compared to F10.7 cm and SSN for low to high solar activity period (2010-2014).

* The overall trends of TEC obtained from GPS and equatorial electrojet (EEJ) strength are similar in all the months of the years 2010-2014. The correlation between GPS-TEC and EEJ strength, showed a positive correlation for the year $2010(r=0.73), 2011(r=0.60), 2012(r=0.76) 2013(r=0.80)$ and 2014 $(\mathrm{r}=0.84)$ (see in Figure 8).

\section{Acknowledgements}

We would like to thank the TEQIP grant, for the procurement of GPS system at SVNIT, Surat. We are thankful to NOAA for solar data (http://www.ngdc.noaa.gov), a for solar EUV data (http://lasp.colorado.edu/lisird/whi_ref_spectra/), and International quiet and disturbed days (IQD/IDD) data (http://www.ga.gov.au/oracle/geomag/iqd_form.jsp).The authors wish to express their sincere thanks to the IIG, Mumbai for providing $\Delta \mathrm{H}$ data.

\section{References}

[1] Appleton, E.V. (1946) Two Anomalies in the Ionosphere. Nature, 157, 691.

[2] Martyn, D.F. (1947) Atmospheric Tides in the Ionosphere. I. Solar Tides in the F2 Region. Proceedings of the Royal Society of London. Series A, Mathematical and Physical Sciences, 189, 241-260. https://doi.org/10.1098/rspa.1947.0037

[3] Hofmann-Wellenhof, B., Lichtenegger, H. and Collins, J. (1992) Global Positioning System, Theory and Practice. 4th Edition, Springer, Berlin, 389. https://doi.org/10.1007/978-3-7091-5126-6

[4] Langley, R., Fedrizzi, M., Paula, E., Santos, M. and Komjathy, A. (2002) Mapping the Low Latitude Ionosphere with GPS. GPS World, 13, 41-46.

[5] Langley, R. (1996) Propagation of the GPS Signals. In: Kleusberg, A. and Teunissen, P., Eds., GPS for Geodesy, Springer, Berlin, Heidelberg, New York, 103-140. https://doi.org/10.1007/bfb0117680

[6] Rama Rao, P.V.S., Venkatesh, K., Prasad, D.S.V.V.D. and Niranjan, K. (2013) On the Uncertainties in the Measurement of Absolute (True) TEC over Indian Equatorial and Low Latitude Sectors. Advances in Space Research, 51, 1238-1252. https://doi.org/10.1016/j.asr.2012.10.032

[7] Chowdhary, V.R., Tripathi, N.K., Arunpold, S. and Raju, D.K. (2015) Variations of Total Electron Content in the Equatorial Anomaly Region in Thailand. Advances in Space Research, 55, 231-242. https://doi.org/10.1016/j.asr.2014.09.024

[8] Ouattara, F. and Fleury, R. (2011) Variability of CODG TEC and IRI 2001 Total Electron Content (TEC) during IHY Campaign Period (21 March to 16 April 2008) at Niamey under Different Geomagnetic Activity Conditions. Scientific Research and Essays, 6, 3609-3622. https://doi.org/10.5897/SRE10.1050

[9] Zoundi, C., Ouattara, F., Fleury, R., Amory-Mazaudier, C. and Duchesne, L.P. (2012) Seasonal TEC Variability in West Africa Equatorial Anomaly Region. European Journal of Scientific Research, 77, 303-313.

[10] Fayose, R.S., Babatunde, R., Oladosu, O. and Groves, K. (2012) Variation of Total 
Electron Content and Their Effect on GNSS over Akure, Nigeria. Applied Physics Research, 4.

[11] D’ujanga, F.M., Mubiru, J., Twinamasiko, B.F., Basalirwa, C. and Ssenyonga, T.J. (2012) Total Electron Content Variations in Equatorial Anomaly Region. Advances in Space Research, 50, 441-449. https://doi.org/10.1016/j.asr.2012.05.005

[12] Oron, S., D'ujanga, F.M. and Ssenyonga, T.J. (2013) Ionospheric TEC Variations during the Ascending Solar Activity Phase at an Equatorial Station, Uganda. Indian Journal of Radio \& Space Physics, 42, 7-17.

[13] Opio, P., D'ujanga, F.M. and Ssenyonga, T. (2015) Latitudinal Variation of the Ionosphere in the African Sector Using GPS TEC Data. Advances in Space Research, 55, 1640-1650. https://doi.org/10.1016/j.asr.2014.12.036

[14] Walker, G.O., Ma, J.H.K. and Golton, E. (1994) The Equatorial Ionospheric Anomaly in Electron Content from Solar Minimum to Solar Maximum for South East Asia. Annales Geophysicae, 12, 195-209. https://doi.org/10.1007/s00585-994-0195-0

[15] Sahai, Y., Becker-Guedes, F. and Fagundes, P.R. (2007) Response of Nighttime Equatorial and Low Latitude F-Region to the Geomagnetic Storm of August 18, 2003, in the Brazilian Sector. Advances in Space Research, 39, 1325-1334. https://doi.org/10.1016/j.asr.2007.02.064

[16] Natali, M.P. and Meza, A. (2011) Annual and Semiannual Variations of Vertical Total Electron Content during High Solar Activity Based on GPS Observations. Annales Geophysicae, 29, 865-873. https://doi.org/10.5194/angeo-29-865-2011

[17] Akala, A.O., Seemala, G.K., Doherty, P.H., Valladares, C.E., Carrano, C.S., Espinoza, J. and Oluyo, S. (2013) Comparison of Equatorial GPS-TEC Observations over an African Station and an American Station, during the Minimum and Ascending Phases of Solar Cycle 24. Annales Geophysicae, 31, 2085-2096. https://doi.org/10.5194/angeo-31-2085-2013

[18] de Abreu, A.J., Fagundes, P.R., Gende, M., Bolaji, O.S., de Jesus, R. and Brunini, C. (2014) Investigation of Ionospheric Response to Two Moderate Geomagnetic Storms Using GPS-TEC Measurements in the South American and African Sectors during the Ascending Phase of Solar Cycle 24. Advances in Space Research, 53, 1313-1328. https://doi.org/10.1016/j.asr.2014.02.011

[19] Zhao, B., Wan, W., Liu, L., Mao, T., Ren, Z., Wang, M. and Christensen, A.B. (2007) Features of Annual and Semiannual Variations Derived from the Global Ionospheric Maps of Total electron Content. Annales Geophysicae, 25, 2513-2527. https://doi.org/10.5194/angeo-25-2513-2007

[20] Liu, G., Huang, W., Gong, J. and Shen, H. (2013) Seasonal Variability of GPS-VTEC and Model during Low Solar Activity Period (2006-2007) near the Equatorial Ionization Anomaly Crest location in Chinese Zone. Advances in Space Research, 51, 366-376. https://doi.org/10.1016/j.asr.2012.09.002

[21] Huo, X.L., Yuan, Y.B., Ou, J.K., Zhang, K.F. and Bailey, G.J. (2009) Monitoring the Global-Scale Winter Anomaly of Total Electron Contents Using GPS Data. Earth, Planets and Space, 61, 1019-1024. https://doi.org/10.1186/BF03352952

[22] Perevalova, N.P., Polyakova, A.S. and Zalizovski, A.V. (2010) Diurnal Variation of the Total Electron Content under Quiet Helio-Geomagnetic Conditions. Journal of Atmospheric and Solar-Terrestrial Physics, 72, 997-1007. https://doi.org/10.1016/j.jastp.2010.05.014

[23] Zakharenkova, I.E., Cherniak, I.V., Krankowski, A. and Shagimuratov, I.I. (2013) Analysis of Electron Content Variations over Japan during Solar Minimum: Observations and Modeling. Advances in Space Research, 52, 1827-1836.

https://doi.org/10.1016/j.asr.2012.09.043 
[24] Venkatesh, K., Fagundes, P.R., Seemala, G.K., de Jesus, R., de Abreu, A.J. and Pillat, V.G. (2014) On the Performance of the IRI-2012 and NeQuick2 Models during the Increasing Phase of the Unusual 24th Solar Cycle in the Brazilian Equatorial and Low-Latitude Sectors. Journal of Geophysical Research: Space Physics, 119, 50875105. https://doi.org/10.1002/2014ja019960

[25] Venkatesh, K., Fagundes, P.R., de Jesus, R., de Abreu, A.J., Pillat, V.G. and Sumod, S.G. (2014) Assessment of IRI-2012 Profile Parameters by Comparison with the Ones Inferred Using NeQuick2, Ionosonde and FORMOSAT-1 Data during the High Solar Activity over Brazilian Equatorial and Low Latitude Sector. Journal of Atmospheric and Solar-Terrestrial Physics, 121, 10-23. https://doi.org/10.1016/j.jastp.2014.09.014

[26] Venkatesh, K., Fagundes, P.R., Prasad, D.S.V.V.D., Denardini, C.M., de Abreu, A.J., Pillat, de Jesus, R. and Gende, M. (2015) Day-to-Day Variability of Equatorial Electrojet and Its Role on the Day-to-Day Characteristics of the Equatorial Ionization Anomaly over the Indian and Brazilian Sectors. Journal of Geophysical Research: Space Physics, 120, 9117-9131.

[27] Karia, S.P. and Pathak, K.N. (2011) GPS Based TEC Measurements for a Period August 2008-December 2009 near the Northern Crest of Indian Equatorial Anomaly Region. Journal of Earth System Science, 120, 851-858. https://doi.org/10.1007/s12040-011-0114-1

[28] Chauhan, V., Singh, O.P. and Singh, B. (2011) Diurnal and Seasonal Variation of GPS-TEC during a Low Activity Period as Observed at A Low Latitude Station Agra. Indian Journal of Radio \& Space Physics, 40, 26-36.

[29] Van Dierendonck, A.J., Fenton, P., Klobuchar, J. and Hua, Q. (1996) Commercial Ionospheric Scintillation Monitoring Receiver Development and Test Results. Proceedings of the 52nd Annual Technical Meeting of the Institute of Navigation, Cambridge, MA, 19-21 June 1996, 573-582.

[30] Sardon, E., Rius, A. and Zarraoa, N. (1994) Estimation of the Transmitter and the Receiver Differential Biases and the Ionospheric Total Electron Content from Global Positioning System Observations. Radio Science, 29, 577-586. https://doi.org/10.1029/94RS00449

[31] Ciraolo, L., Azpilicueta, F., Brunini, C., Meza, A. and Radicella, S.M. (2007) Calibration Errors on Experimental Slant Total Electron Content (TEC) Determined with GPS. Journal of Geodesy, 81, 111-120. https://doi.org/10.1007/s00190-006-0093-1

[32] Norsuzila, Y., Abdullah, M., Ismail, M. and Zaharim, A. (2009) Model Validation for Total Electron Content (TEC) at an Equatorial Region. European Journal of Scientific Research, 28, 642-648.

[33] Brunini, C. and Azpilicueta, F. (2010) GPS Slant Total Electron Content Accuracy Using the Single Layer Model under Different Geomagnetic Regions and Ionospheric Conditions. Journal of Geodesy, 84, 293-304. https://doi.org/10.1007/s00190-010-0367-5

[34] Karia, S.P., Pathak, K.N., Yadav, K.S., Chaudhary, N.P., Patel, N.C. and Jana, R. (2014) Modification in Atmospheric Refractivity and GPS Based TEC as Earthquake Precursors. Positioning, 5, 46-52. https://doi.org/10.4236/pos.2014.52006

[35] Karia, S.P., Patel, N.C. and Pathak, K.N. (2015) Comparison of GPS Based TEC Measurements with the IRI-2012 Model for the Period of Low to Moderate Solar Activity (2009-2012) at the Crest of Equatorial Anomaly in Indian Region. Advances in Space Research, 55, 1965-1975. https://doi.org/10.1016/j.asr.2014.10.026

[36] Karia, S.P., Patel, N.C. and Pathak, K.N. (2016) A Comparison of TEC Predicted by IRI-2012 with That Measured at Three Different Stations in Low Latitude Indian 
Region for the Years (2010-2012). Advances in Space Research, in press.

[37] Patel, N.C., Karia, S.P. and Pathak, K.N. (2016) Comparison of GPS-Derived TEC with IRI-2012 and IRI-2007 TEC Predictions at Surat, a Location around the EIA Crest in the Indian Sector, during the Ascending Phase of Solar Cycle 24. Advances in Space Research. (In Press)

[38] Mannucci, A.J., Wilson, B.D. and Edwards, C.D. (1993) A New Method for Monitoring the Earth's Ionospheric Total Electron Content Using the GPS Global Network. Proceedings of the 6 th International Technical Meeting of the Satellite Division of The Institute of Navigation, Salt Lake City, UT, 22-24 September 1993, 1323-1332.

[39] Rama Rao, P.V.S., Gopi Krishna, S., Niranjan, K. and Prasad, D.S.V.V.D. (2006) Temporal and Spatial Variations in TEC Using Simultaneous Measurements from the Indian GPS Network of Receivers during the Low Solar Activity Period of 2004-2005. Annales Geophysicae, 24, 3279-3292.

https://doi.org/10.5194/angeo-24-3279-2006

[40] Rastogi, R.G. and Klobuchar, J.A. (1990) Ionospheric Electron Content within the Equatorial $\mathrm{F}_{2}$ Layer Anomaly Belts. Journal of Geophysical Research: Space Physics, 95, 19045-19052. https://doi.org/10.1029/JA095iA11p19045

[41] Nair, K.N., Rastogi, R.G. and Sarabhai, V.A. (1970) Daily Variation of the Geomagnetic Field at the Dip Equator. Nature, 226, 740-741.

[42] Alex, S. and Mukherjee, S. (2001) Local Time Dependence of the Equatorial Counter Electrojet Effect in a Narrow Longitudinal Belt. Earth, Planets and Space, 53, 1151-1161. https://doi.org/10.1186/BF03352410

[43] Aggarwal, M., Joshi, H.P., Iyer, K.N., Kwak, Y.S., Lee, J.J., Chandra, H. and Cho, K.S. (2012) Day-to-Day Variability of Equatorial Anomaly in GPS-TEC during Low Solar Activity Period. Advances in Space Research, 49, 1709-1720. https://doi.org/10.1016/j.asr.2012.03.005

[44] Bagiya, M.S., Joshi, H.P., Iyer, K.N., Aggarwal, M., Ravindran, S. and Pathan, B.M. (2009) TEC Variations during Low Solar Activity Period (2005-2007) near the Equatorial Ionospheric Anomaly Crest Region in India. Annales Geophysicae, 27, 1047-1057. https://doi.org/10.5194/angeo-27-1047-2009

[45] Kumar, S. (2016) Performance of IRI-2012 Model during a Deep Solar Minimum and a Maximum Year over Global Equatorial Regions. Journal of Geophysical Research: Space Physics, 121, 5664-5674. https://doi.org/10.1002/2015ja022269

[46] Kane, R.P. (1980) Irregular Variations in the Global Distribution of Total Electron Content. Radio Science, 15, 837-842. https://doi.org/10.1029/RS015i004p00837

[47] Modi, R.P. and Iyer, K.N. (1989) IEC and Slab Thickness near the Peak. Indian Journal of Radio \& Space Physics, 18, 23-26.

[48] Tariku, Y.A. (2015) TEC Prediction Performance of IRI-2012 Model during a Very Low and a High Solar Activity Phase over Equatorial Regions, Uganda. Journal of Geophysical Research: Space Physics, 120, 5973-5982. https://doi.org/10.1002/2015ja021203

[49] Jonah, O.F., de Paula, E.R., Muella, M.T.A.H., Dutra, S.L.G., Kherani, E.A., Negreti, P.M.S. and Otsuka, Y. (2015) TEC Variation during High and Low Solar Activities over South American Sector. Journal of Atmospheric and Solar-Terrestrial Physics, 135, 22-35. https://doi.org/10.1016/j.jastp.2015.10.005

[50] Titheridge, J.E. (1974) Changes in Atmospheric Composition Inferred from Ionospheric Production Rates. Journal of Atmospheric and Terrestrial Physics, 36, 1249 1254. https://doi.org/10.1016/0021-9169(74)90111-1 
[51] Oryema, B., Jurua, E., D’ujanga, F.M. and Ssebiyonga, N. (2015) Investigation of TEC Variations over the Magnetic Equatorial and Equatorial Anomaly Regions of the African Sector. Advances in Space Research, 56, 1939-1950. https://doi.org/10.1016/j.asr.2015.05.037

[52] Kumar, S., Priyadarshi, S., Gopi Krishna, S. and Singh, A.K. (2012) GPS-TEC Variations during Low Solar Activity Period (2007-2009) at Indian Low Latitude Stations. Astrophysics and Space Science, 339, 165-178. https://doi.org/10.1007/s10509-011-0973-6

[53] Jonah, O., de Paula, E. and Kherani, A. (2013) Observations and Simulations of Equinoctial Asymmetry during Low and High Solar Activities. 13th International Congress of the Brazilian Geophysical Society \& EXPOGEF, Rio de Janeiro, Brazil, 26-29 August 2013, 1906-1909.

[54] Sharma, K., Dabas, R.S. and Ravindran, S. (2012) Study of Total Electron Content Variations over Equatorial and Low Latitude Ionosphere during Extreme Solar Minimum. Astrophysics and Space Science, 341, 277-286. https://doi.org/10.1007/s10509-012-1133-3

[55] Huang, Y.N. and Cheng, K. (1996) Solar Cycle Variation of Equatorial Ionospheric Anomaly in Total Electron Content in the Asian Region. Journal of Geophysical Research: Space Physics, 101, 24513-24520. https://doi.org/10.1029/96JA01297

[56] Bhuyan, P.K. and Borah, R.R. (2007) TEC Derived from GPS Network in India and Comparison with the IRI. Advances in Space Research, 39, 830-840. https://doi.org/10.1016/j.asr.2006.12.042

[57] Mukherjee, S., Sarkar, S., Purohit, P.K. and Gwal, A.K. (2010) Seasonal Variation of Total Electron Content at Crest of Equatorial Anomaly Station during Low Solar Activity Conditions. Advances in Space Research, 46, 291-295. https://doi.org/10.1016/j.asr.2010.03.024

[58] Prasad, S.N.V.S., Rama Rao, P.V.S., Prasad, D.S.V.V.D., Venkatesh, K. and Niranjan, K. (2012) On the Variabilities of the Total Electron Content (TEC) over the Indian Low Latitude Sector. Advances in Space Research, 49, 898-913. https://doi.org/10.1016/j.asr.2011.12.020

[59] Kumar, S., Singh, A.K. and Lee, J. (2014) Equatorial Ionospheric Anomaly (EIA) and Comparison with IRI Model during Descending Phase of Solar Activity (20052009). Advances in Space Research, 53, 724-733. https://doi.org/10.1016/j.asr.2013.12.019

[60] Tyagi, T.R. and Gupta, A.D. (1990) Beacon Satellite Studies and Modeling of Total Electron Contents of the Ionosphere. Indian Journal of Radio and Space Physics, 19, 424-438.

[61] Lin, C.H., Liu, J.Y., Fang, T.W., Chang, P.Y., Rsai, H.F., Chen, C.H. and Hsiao, C.C. (2007) Motions of the Equatorial Ionization Anomaly Crests Imaged by FORMOSAT-3/COSMIC. Geophysical Research Letters, 34, L19101. https://doi.org/10.1029/2007gl030741

[62] Chauhan, V. and Singh, O.P. (2010) A Morphological Study of GPS-TEC Data at Agra and Their Comparison with the IRI Model. Advances in Space Research, 46, 280-290. https://doi.org/10.1016/j.asr.2010.03.018

[63] Galav, P., Dashora, N., Sharma, S. and Pandey, R. (2010) Characterization of Low Latitude GPS-TEC during Very Low Solar Activity Phase. Journal of Atmospheric and Solar-Terrestrial Physics, 72, 1309-1317.

https://doi.org/10.1016/j.jastp.2010.09.017

[64] Bhuyan, P. and Hazarika, R. (2013) GPS TEC near the Crest of the EIA at $95^{\circ} \mathrm{E}$ 
during the Ascending Half of Solar Cycle 24 and Comparison with IRI Simulations. Advances in Space Research, 52, 1247-1260. https://doi.org/10.1016/j.asr.2013.06.029

[65] Balan, N., Rajesh, P.K., Sripathi, S., Tulasiram, S., Liu, J.Y. and Bailey, G.J. (2013) Modeling and Observations of the North-South Ionospheric Asymmetry at Low Latitudes at Long Deep Solar Minimum. Advances in Space Research, 52, 375-382. https://doi.org/10.1016/j.asr.2013.04.003

[66] Kumar, S., Patel, K. and Singh, A.K. (2015) TEC Variation over an Equatorial and Anomaly Crest Region in India during 2012 and 2013. GPS Solutions, 20, 1-10.

[67] Rishbeth, H. and Garriott, O.K. (1969) Introduction to Ionospheric Physics. 1st Edition, Academic Press, New York, 47, 234 p.

[68] Krankowsky, D., Kasprazak, W.T. and Nier, A.O. (1968) Mass Spectrometric Studies of the Composition of the Lower Thermosphere during Summer 1967. Journal of Geophysical Research, 73, 7291-7306. https://doi.org/10.1029/JA073i023p07291

[69] Cox, L.P. and Evans, J.V. (1970) Seasonal Variation of the $\mathrm{O} / \mathrm{N}_{2}$ Ratio in the $F_{1} \mathrm{Re}-$ gion. Journal of Geophysical Research, 75, 6271-6286.

https://doi.org/10.1029/JA075i031p06271

[70] Torr, M.R. and Torr, D.G. (1973) The Seasonal Behaviour of the F2-Layer of the Ionosphere. Journal of Atmospheric and Terrestrial Physics, 35, 2237-2251. https://doi.org/10.1016/0021-9169(73)90140-2

[71] Hazarika, R. and Bhuyan, P.K. (2014) Spatial Distribution of TEC across India in 2005: Seasonal Asymmetries and IRI Prediction. Advances in Space Research, 54, 1751-1767. https://doi.org/10.1016/j.asr.2014.07.011

[72] Yadav, S., Dabas, R.S., Das, R.M., Upadhayaya, A.K. and Gwal, A.K. (2013) Temporal and Spatial Variation of Equatorial Ionization Anomaly by Using Multistation Ionosonde Data for the 19th Solar Cycle over the Indian Region. Advances in Space Research, 51, 1253-1265. https://doi.org/10.1016/j.asr.2012.11.009

[73] Dabas, R.S., Lakshmi, D.R. and Reddy, B.M. (1993) Solar Activity Dependence of Ionospheric Electron Content and Slab Thickness Using Different Solar Indices. Pure and Applied Geophysics, 140, 721-728. https://doi.org/10.1007/BF00876585

[74] Gupta, J.K. and Singh, L. (2001) Long Term Ionospheric Electron Content Variations over Delhi. Annales Geophysicae, 18, 1635-1644.

https://doi.org/10.1007/s00585-001-1635-8

[75] Chakraborty, S.K. and Hajra, R. (2007) Solar Control of Ambient Ionization of the Ionosphere near the Crest of the Equatorial Anomaly in the Indian Zone. The Bulletin of the Astronomical Society of India, 35, 599-605.

[76] Liu, G., Huang, W., Shen, H. and Gong, J. (2012) Vertical TEC Variations and Model during Low Solar Activity at a Low Latitude Station, Xiamen. Advances in Space Research, 49, 530-538. https://doi.org/10.1016/j.asr.2011.10.024

[77] Liu, L., Wan, W., Ning, B. and Zhang, M.L. (2009) Climatology of the Mean TEC Derived from GPS Global Ionospheric Maps. Journal of Geophysical Research: Space Physics, 114, Article ID: A06308.

[78] Wu, C.C., Fry, C.D., Liu, J.Y., Liou, K. and Tseng, C.L. (2004) Annual TEC Variation in the Equatorial Anomaly Region during the Solar Minimum: September 1996-August 1997. Journal of Atmospheric and Solar-Terrestrial Physics, 66, 199 207. https://doi.org/10.1016/j.jastp.2003.09.017

[79] Wu, C.-C., Liou, K., Shan, S.-J. and Tseng, C.L. (2008) Variation of Ionospheric Total Electron Content in Taiwan Region of the Equatorial Anomaly from 1994 to 2003. Advances in Space Research, 41, 611-616. 
https://doi.org/10.1016/j.asr.2007.06.013

[80] Zhao, B., Wan, W., Liu, L., Mao, T. and Ren, Z. (2009) Characteristics of the Ionospheric Total Electron Content of the Equatorial Ionization Anomaly in the Asian-Australian Region during 1996-2004. Annales Geophysicae, 27, 3861-3873. https://doi.org/10.5194/angeo-27-3861-2009

[81] Kumar, S. and Singh, A.K. (2009) Variation of Ionospheric Total Electron Content in Indian Low Latitude Region of the Equatorial Anomaly during May 2007-April 2008. Advances in Space Research, 43, 1555-1562. https://doi.org/10.1016/j.asr.2009.01.037

[82] Chen, Y., Liu, L. and Wan, W. (2011) Does the F-10. 7 Index Correctly Describe Solar EUV Flux during the Deep Solar Minimum of 2007-2009? Journal of Geophysical Research: Space Physics, 116, 1451-1453.

[83] Maruyama, T. (2010) Solar Proxies Pertaining to Empirical Ionospheric Total Electron Content Models. Journal of Geophysical Research: Space Physics, 115, A04306.

[84] Maruyama, T. (2011) Modified Solar Flux Index for Upper Atmospheric Applications. Journal of Geophysical Research: Space Physics, 116, A08303.

[85] Yadav, K.S., Karia, S.P. and Pathak, K.N. (2015) Removal of Solar Radiation Effect Based on Nonlinear Data Processing Technique for Seismo-Ionospheric Anomaly before Few Earthquakes. Geomatics, Natural Hazards and Risk, 7, 1147-1161. https://doi.org/10.1080/19475705.2015.1021864

[86] Rishbeth, H. and Mendillo, M. (2001) Patterns of F2-Layer Variability. Journal of Atmospheric and Solar-Terrestrial Physics, 63, 1661-1680. https://doi.org/10.1016/S1364-6826(01)00036-0

[87] Sethia, G., Rastogi, R.G., Deshpande, M.R. and Chandra, H. (1980) Equatorial Electrojet Control of the Low Latitude Ionosphere. Journal of Geomagnetism and Geoelectricity, 32, 207-216. https://doi.org/10.5636/jgg.32.207

[88] Aravindan, P. and Iyer, K.N. (1990) Day to Day Variability in Ionospheric Electron Content at Low Latitudes. Planetary and Space Science, 38, 743-750. https://doi.org/10.1016/0032-0633(90)90033-M

[89] Chapman, S. (1951) The Equatorial Electrojet as Detected from the Abnormal Electric Current Distribution above Huancayo, Peru, and Elsewhere. Archiv für Meteorologie, Geophysik und Bioklimatologie. Serie A, 4, 368-390. https://doi.org/10.1007/BF02246814

[90] Chakrabarty, D., Bagiya, M.S., Thampi, S.V. and Iyer, K.N. (2012) Solar EUV Flux $(0.1-50 \mathrm{~nm})$, F10. $7 \mathrm{~cm}$ Flux, Sunspot Number and the Total Electron Content in the Crest Region of Equatorial Ionization Anomaly during the Deep Minimum between Solar Cycle 23 and 24. Indian Journal of Radio \& Space Physics, 41, 110-120.

[91] Shimeis, A., Mazaudier, C.A., Fleury, R., Mahrous A.M. and Hassan, A.F. (2014) Transient Variations of Vertical Total Electron Content over Some African Stations from 2002 to 2012. Advances in Space Research, 54, 2159-2171.

https://doi.org/10.1016/j.asr.2014.07.038 
Submit or recommend next manuscript to SCIRP and we will provide best service for you:

Accepting pre-submission inquiries through Email, Facebook, LinkedIn, Twitter, etc. A wide selection of journals (inclusive of 9 subjects, more than 200 journals)

Providing 24-hour high-quality service

User-friendly online submission system

Fair and swift peer-review system

Efficient typesetting and proofreading procedure

Display of the result of downloads and visits, as well as the number of cited articles Maximum dissemination of your research work

Submit your manuscript at: http://papersubmission.scirp.org/

Or contact pos@scirp.org 